\title{
Teenage pregnancy outcomes in a rural area of South India: A prospective study
}

Chandrika R. Doddihal, Sangappa M. Katti', Maheshwar D. Mallapur ${ }^{1}$

Department of Community Medicine, Shri B. M. Patil Medical College, BLDE University, Bijapur, ${ }^{1}$ Department of Community

Medicine, J. N. Medical College, KLE University, Belgaum, Karnataka, India

Address for the Correspondence: Dr. Chandrika R. Doddihal, Department of Community Medicine, Shri B. M. Patil Medical College, BLDE University, Bijapur - 586 103, Karnataka, India. E-mail: chandrika02@gmail.com

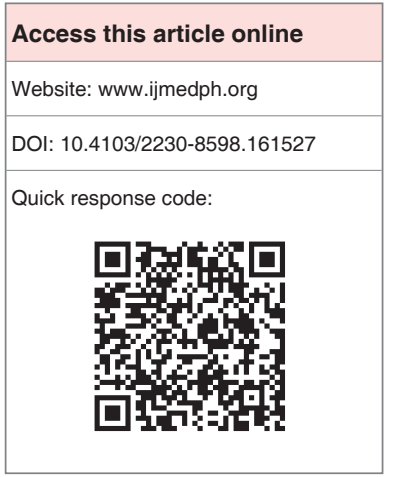

Context: Teenage pregnancy is dangerous for the mother, child and the community, and teenage girls are twice as likely to die of pregnancy and childbirth related complications as opposed to older women. Aims: (1) To know the outcomes of teenage pregnancies. (2) To study the sociodemographic profile of teenage pregnancies. Study Design: A longitudinal study. Study Setting: Vantamuri Primary Health Centre-Rural field practice area of Jawaharlal Nehru Medical College Belgaum. Materials and Methods: A total of 144 teenage pregnant women, aged between 15 and 19 years were selected and information on sociodemographic variables, and pregnancy outcome was recorded in 3 visits. Statistical Analysis: Percentages and Ratios, Chi-square test to find an association between various study variables. Results: In the current study majority, $66.0 \%$ participants were of $18-19$ years age, $90.3 \%$ adolescents were housewives and $53.5 \%$ had studied high school and beyond. The mean age of marriage was 16 years, and $79.2 \%$ of them were primigravidae. Traditional practice $(68.8 \%)$ was the commonest reason for early marriage, and family pressure $(46.5 \%)$ was the often cited reason for early pregnancy. Live births were noted in $93.1 \%$ teenagers, stillbirths and abortions were present in $4.8 \%$ and $2.1 \%$ teens respectively. Age and previous pregnancies affected the outcome. Conclusion: The mean age of participants was 17.8 years, and that of marriage was 16 years and this occurrence of pregnancy in teenage leads to adverse outcomes. Thus, periodic Information, Education and Communication activities have to be held, and child marriage act has to be strictly enforced to improve their health.

Key words: Outcome, rural south India, teenage pregnancy

\section{INTRODUCTION}

"Teenage" or "Adolescence" is the transition from childhood to adulthood. It is defined by the World Health Organization as period between 10 and 19 years of age. Adolescence represents a key stage in the development and a critical opportunity for ensuring a successful transition to adulthood. ${ }^{[1]}$

In recent decades, adolescent pregnancy has become an important health issue in a great number of countries, both developed and developing. Most teenage marriages lead to the teenage motherhood. The latest international estimates indicate that worldwide $>60$ million women aged 20-24 years were married before the age of 18 years and about 16 million women 15-19 years old give birth each year, representing $11.0 \%$ of all births worldwide. Ironically, half of all adolescent births occur in just seven countries: Bangladesh, Brazil, the Democratic Republic of the Congo, Ethiopia, India, Nigeria and the United States. ${ }^{[2]}$

Adolescent pregnancy is on the rise, emerging as a serious problem all over the world and more so in developing countries like India where early marriages and early pregnancies are long established and well-accepted customs. ${ }^{[3]}$ Teenage pregnancy is dangerous for the mother, child and the community. Although teens aged 10-19 years account for $11.0 \%$ of all births worldwide, they account for $23.0 \%$ of the overall burden of disease due to pregnancy and childbirth. ${ }^{[4]}$ Medical complications such as preterm labor, pregnancy-induced hypertension, anemia and low birth weight babies are strongly associated with adolescent pregnancy.

While there is growing recognition of the need for action to promote adolescent reproductive health, work done in this regard is often piecemeal. In this background, as no study about teenage pregnancy was 
done in this area, a study to know the outcomes and sociodemographic factors associated with adolescent pregnancy was taken up.

\section{MATERIALS AND METHODS}

A community-based prospective study was carried out in a rural primary health center area comprising of 5 subcenters, which is the field practice area of Jawaharlal Nehru Medical College, Belgaum. Approximate pregnant women in that area were 655 and considering teenage pregnant women to be $20.9 \%$ (National Family Health Survey-3), a total of 144 adolescent pregnant women, aged between 15 and 19 years were selected for the study and the duration of the study was for 1-year from January 1, 2012 to December 31, 2012. The study included three visits with first being enrolment, second between 28 and 36 weeks of gestation and third in their postpartum period between 0 and 30 days to record their outcome. Women were interviewed with a predesigned, pretested questionnaire to know about their sociodemographic details on first visit and pregnancy details in subsequent visits.

\section{Statistics}

Numerical sociodemographic variables were analyzed by means and standard deviations, and categorical data were summarized using percentages. Chi-square test was used to find the association between various sociodemographic variables and teenage pregnancy outcomes.

\section{RESULTS}

In the current study, majority $95(66.0 \%)$ participants were between 18 and 19 years age, with their mean age being $17.8+1.1$ years, and $127(88.2 \%)$ were Hindus by religion. As many as $130(90.3 \%)$ teens were housewives and $48(33.3 \%)$ of their husbands were factory workers. A large number of teenagers and their husbands had studied up to high school and above $(53.5 \%$ and $50.7 \%$ respectively). Most, $65(45.1 \%)$ of the teens belonged to class IV socioeconomic status as per modified B G Prasad classification and 110 (76.4\%) were living in a joint family [Table 1].

A great number of study participants, $90.9 \%$ had married in the age group of 15-19 years and the mean age of marriage was 16 years. A total of $34.0 \%$ had consanguineous marriage and traditional practices $(68.8 \%)$ were the commonest reason for early marriage and family pressure $(46.5 \%)$ was the often cited reason for early pregnancy [Table 2].

About $79.2 \%$ of them were primigravidae, and $81.9 \%$ of the participants had registered their pregnancy within 12 weeks of gestation. A total of $79.2 \%$ had taken adequate antenatal care (ANC) visits, and all of the teenagers in the study had taken iron and folic acid and tetanus toxoid injections as necessary [Table 3].

\section{Pregnancy outcome}

A majority of teens, $92(63.9 \%)$ had full term normal delivery followed by $38(26.4 \%)$ had preterm delivery, 7 (4.8\%) had stillbirth, $3(2.1 \%)$ had abortion, and there were 4 (2.8\%) neonatal deaths [Figure 1]. Adverse outcomes like still birth, abortions and neonatal death occurred more in adolescents aged 15-17 years than 18-19 years and this difference was found to be statistically significant $(P<0.05)$ and also occurred more in multigravidae as compared to primigravidae,

\begin{tabular}{|c|c|c|}
\hline Characteristics & Number & Percentage \\
\hline \multicolumn{3}{|l|}{ Age } \\
\hline $15-17$ & 49 & 34.0 \\
\hline $18-19$ & 96 & 66.0 \\
\hline \multicolumn{3}{|l|}{ Religion } \\
\hline Hindu & 127 & 88.2 \\
\hline NonHindus & 17 & 11.8 \\
\hline \multicolumn{3}{|l|}{ Participant's occupation } \\
\hline Homemaker & 130 & 90.3 \\
\hline Employed & 14 & 9.7 \\
\hline \multicolumn{3}{|l|}{ Husband's occupation } \\
\hline Agriculturist & 42 & 29.2 \\
\hline Laborer & 39 & 27.1 \\
\hline Factory worker & 48 & 33.3 \\
\hline Others & 15 & 10.4 \\
\hline \multicolumn{3}{|l|}{ Education } \\
\hline Illiterate & 29 & 20.1 \\
\hline Primary school & 38 & 26.4 \\
\hline High school and above & 77 & 53.5 \\
\hline \multicolumn{3}{|l|}{ Husband's education } \\
\hline Illiterate & 34 & 23.6 \\
\hline Primary school & 37 & 25.7 \\
\hline High school and above & 73 & 50.7 \\
\hline \multicolumn{3}{|l|}{ Family type } \\
\hline Joint family & 110 & 76.4 \\
\hline Nuclear family & 34 & 23.6 \\
\hline \multicolumn{3}{|c|}{$\begin{array}{l}\text { Socioeconomic status } \\
\text { (modified B G Prasad classification) }\end{array}$} \\
\hline Class I & 0 & 0.0 \\
\hline Class II & 15 & 10.4 \\
\hline Class III & 38 & 26.4 \\
\hline Class IV & 65 & 45.1 \\
\hline Class V & 26 & 18.1 \\
\hline
\end{tabular}

\begin{tabular}{|c|c|c|}
\hline Characteristics & Number & Percentage \\
\hline \multicolumn{3}{|l|}{ Age at marriage (years) } \\
\hline$<10$ & 6 & 4.2 \\
\hline $10-14$ & 7 & 4.9 \\
\hline $15-19$ & 131 & 90.0 \\
\hline \multicolumn{3}{|l|}{ Consanguineous marriage } \\
\hline Yes & 49 & 34.0 \\
\hline No & 95 & 66.0 \\
\hline \multicolumn{3}{|l|}{ Reasons for early marriage } \\
\hline Consanguineous & 23 & 16.0 \\
\hline Traditional practices & 99 & 68.8 \\
\hline Unable to pay for education & 3 & 2.1 \\
\hline Other siblings to be married & 19 & 13.1 \\
\hline
\end{tabular}




\begin{tabular}{lcc}
\multicolumn{3}{l}{$\begin{array}{l}\text { Table 3: Distribution of participants according to } \\
\text { pregnancy related events }(\boldsymbol{n}=\mathbf{1 4 4})\end{array}$} \\
$\begin{array}{l}\text { Number } \\
\text { Characteristics }\end{array}$ & Percentage \\
\hline Reasons for early pregnancy & 67 & \\
$\quad$ Family pressure & 47 & 36.5 \\
$\quad$ Tradition & 30 & 20.9 \\
$\quad$ Lack of awareness about contraception & & \\
Previous pregnancies & 114 & 79.2 \\
0 (primigravidae) & 28 & 19.4 \\
1 & 2 & 1.4 \\
2 & & \\
Pregnancy registration & 118 & 81.9 \\
$\quad<12$ weeks & 26 & 18.1 \\
$\quad>12$ weeks & & \\
ANC visits & 114 & 79.2 \\
$\quad$ Adequate & 30 & 20.8 \\
Inadequate & &
\end{tabular}

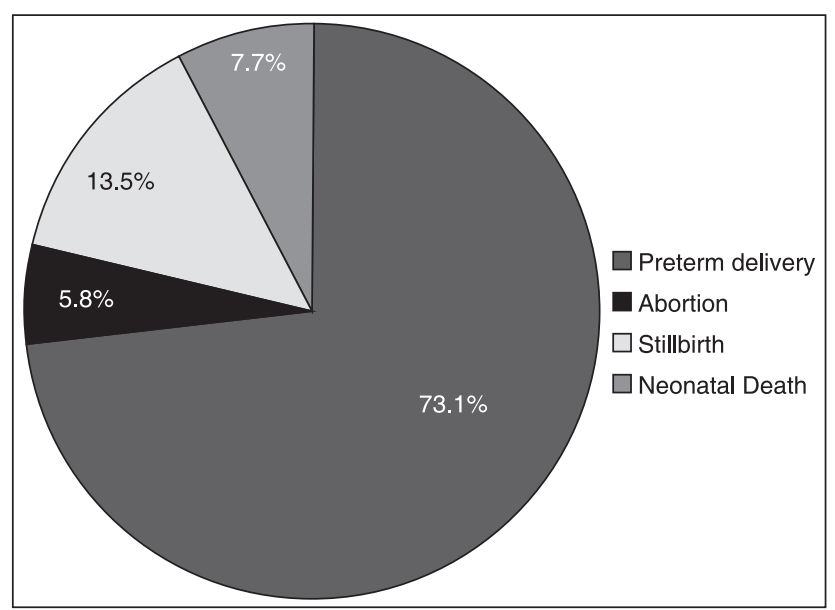

Figure 1: Distribution of participants according to pregnancy outcome $(n=144)$

which was also established to be statistically significant $(P<0.01)$. However, there were no statistical significant associations observed between educational level, occupation and socioeconomic status with pregnancy outcome.

\section{DISCUSSION}

In the present study, the mean age among the study population was $17.8 \pm 1.1$ years, $88.2 \%$ were Hindus by religion, a majority, $90.3 \%$ were housewives and $33.3 \%$ of husbands' of participants were factory workers. A major number of teenagers and their husbands had studied up to high school and beyond (53.5\%) and most of them belonged to Class IV socioeconomic status. These findings were in consistence with the studies conducted at Bengaluru ${ }^{[3]}$ and Delhi..$^{[5]}$

In this study, $90.9 \%$ girls got married between 18 and 19 years and the mean age of marriage was $16+2$ years and $79.2 \%$ adolescents were primigravidae while $19.4 \%$ had previous 1 pregnancy. As a consequence of early marriage, there was early pregnancy and lower education status and accordingly lower socioeconomic status among the teens. The most common reason for early marriage in this study was its traditional practice that was seen in $68.8 \%$ participants and the commonest reason for early pregnancy was family pressure (46.5\%) followed by tradition (32.6\%). Probably, good education and knowledge about the hazards of adolescent pregnancy in the community would have resulted in alteration in traditional practices and thereby decreasing early marriages and by this means early pregnancies. Although, pregnancy registration and ANC taken was high, it can be improved with proper awareness regarding pregnancy complications.

Pregnancy outcomes in majority were live births $(63.9 \%$ were fullterm and $29.2 \%$ were preterm birth), $4.8 \%$ delivered stillborn babies and $2.1 \%$ had abortions that were similar to the studies done at Delhi ${ }^{\left[{ }^{[]}\right]}$and Kolkata. ${ }^{[7]}$

\section{CONCLUSION}

The current study revealed that teen pregnant women were more between 18 and 19 years of age, were housewives, married early due to traditional practices and got pregnant early due to family pressure. Various factors like age, education, occupation, socioeconomic status, previous pregnancies influenced the outcome of teenage pregnancy. Hence, the present study recommends that in order to improve the health of the adolescents, periodic Information, Education and Communication activities have to be held at villages and people, principally elders, need to be told about complications and ill effects of teenage pregnancy. Child marriage act must be stringently imposed to restrain child marriages.

\section{REFERENCES}

1. Park K. Park's Textbook of Preventive and Social Medicine. $21^{\text {st }}$ ed. Jabalpur, India: Banarasidas Bhanot; 2011. p. 489, 97.

2. WHO. Adolescent pregnancy: Issues in adolescent health and development. Geneva: World Health Organisation; 2004. p. 4-10. Available from: http://www.who.int/maternal_child_adolescent/documents. [Last accessed on 2012 Apr 25].

3. Parasuramalu BG, Shakila N, Masthi RN. A study on teenage pregnant mothers attending primary health centers of Kempegowda institute of medical sciences, Bangalore. Indian J Public Health 2010;54:205-8.

4. Government of India. National Family Health Survey-3 Report. New Delhi: Ministry of Health and Family Welfare; 2005-2006. p. 3-24.

5. Sharma AK, Chhabra P, Gupta P, Aggarwal QP, Lyngdoh T. Pregnancy in adolescents: A community based study. Indian J Prev Soc Med 2003;34:24-32.

6. Saxena P, Salhan S, Chattopadhyay B, Kohli MP, Nandan D, Adhish SV. Obstetric and perinatal outcome of teenage and older primigravidas - A retrospective analysis. Health Popul Perspect Issues 2010;33:16-22.

7. Mukhopadhyay P, Chaudhuri RN, Paul B. Hospital-based perinatal outcomes and complications in teenage pregnancy in India. $\mathrm{J}$ Health Popul Nutr 2010;28:494-500.

How to cite this article: Doddihal CR, Katti SM, Mallapur MD. Teenage pregnancy outcomes in a rural area of South India: A prospective study. Int J Med Public Health 2015;5:222-4.

Source of Support: Nil, Conflicts of Interest: None declared. 